Área Abierta. Revista de comunicación

audiovisual y publicitaria

ISSN: 1578-8393 / ISSNe: 1578-8393

\title{
Imágenes en la Crisis Mediterránea: la creación de la imagen pública de Nasrallah
}

\author{
Nadia McGowan ${ }^{1}$ Pablo Rey García ${ }^{2}$
}

Recibido: 13 de diciembre de 2017 / Aceptado: 19 de marzo de 2018

Resumen. La presente investigación se propone analizar la imagen de Nasrallah como líder carismático de Hezbollah, a partir de la definición de Weber y las aportaciones de House. Este análisis se realiza a partir de la imagen que se crea de su persona mediante discursos televisivos, cartelería y en espacios de ocio, como el Mleeta Landmark. Se introducen también las características de los discursos democráticos y de la propaganda terrorista para comprobar qué rasgos están presentes en su oratoria. Se concluye que mediante estas técnicas, se configura como una figura carismática, cercana y omnipotente de gran impacto social gracias a la combinación de las estrategias descritas.

Palabras clave: Hezbollah, Nasralla, carteles políticos, líder carismático, Mleeta

\section{[en] Images in the Mediterranean Crisis: the creation of Nasrallah's public image}

Abstract. The present research aims to analyze Nasrallah's image as Hezbollah's charismatic leader, as defined by Weber and House's contributions. This analysis is based on the image created of his persona through televised speeches, posters and entertainment venues such as Mleeta Landmark. The characteristics of democratic discourse and terrorist propaganda are also introduced in order to ascertain which traits are present in his oratory. We conclude that, through these techniques, he is defined as a charismatic figure which is both accessible and omnipotent, with a great social impact due to the combination of the aforementioned strategies.

Keywords: Hezbollah, Nasralla, Political Posters, Charismatic Leader, Mleeta

Sumario. 1. Introduccion. 2. La figura de Nasrallah 3. El discurso televisivo 4. La cartelería 5. La imagen de líder a través del ocio: el parque de atracciones. 6. Conclusiones 7. Bibliografía

Cómo citar: McGowan, N. y Rey García, P. (2018) Imágenes de la Crisis Mediterránea: la creación de la imagen pública de Nasrallah, en Área Abierta. Revista de comunicación audiovisual y publicitaria, 18 (2), 325-340. http://dx.doi.org/10.5209/ARAB.58330

1 Universidad Complutense de Madrid (España)

E-mail: nmcgowan@gmail.com

2 Universidad Pontificia de Salamanca (España)

E-mail: preyga@upsa.es 


\section{Introducción}

Hezbollah, el "Partido de Dios" libanés ha llevado a cabo grandes esfuerzos para cultivar la imagen de líder de su secretario general, Hassan Nasrallah. Su figura ha sido esencial para la imagen pública del grupo desde que se le nombró secretario general en 1992 y se volvió cada vez más relevante a partir de los acontecimientos bélicos del año 2000 y 2006 . A fecha de hoy, no es solamente la cabeza visible del partido, sino una figura de alta visibilidad e influencia en la sociedad del país. Su imagen está presente en el espacio público tanto por su presencia televisiva como en cartelería e incluso en centros de ocio.

Aunque este breve estudio no aspira a un análisis en profundidad de las dinámicas de Hezbollah, sí se aspira a describir estrategias que configuran la imagen pública de su líder, Hassan Nasrallah, de forma análoga a las de un líder carismático. A la vez, esto puede crear una base desde la cual encontrar formas objetivas de valorar cómo el público lo percibe y cómo la personalidad legitima el liderazgo. Este análisis se realiza a partir de tres espacios donde está presente: su imagen en discursos televisivos, la cartelería callejera y su presencia en espacios de ocio militante. A través de estos medios, se visibiliza su figura como cabeza de Hezbollah y se valida su persona como icono político-religioso.

Sayyid Hassan Nasrallah supone un líder chií de habla árabe, en un lugar del mundo predominantemente sunní. La importancia de Hezbollah, la organización que dirige, en este sentido ha crecido en los últimos años. Hezbollah organizó milicias chiís para combatir a los americanos en Irak en 2003 (Hubbard, 2017), y ha mandado combatientes a Siria y Yemen, y ha preparado grupos de afganos listos para combatir en cualquier conflicto. El Partido de Dios, Hezbollah, es el brazo armado del Vilayat-e Faqih, es decir, del supremo líder del islam para los chiís, actualmente el Ayatolá Alí Jamenei. Por tanto, Nasrallah no es un líder absoluto, y tiene conciencia de su subordinación. Ello no le impide hacer bandera conjunta de Líbano y de Hezbollah, defendiendo ambos intereses a la vez.

En su libro Economy and Society, Max Weber describe tres tipos de autoridad: legal-racional, tradicional y carismático (Weber, 1968). En este artículo nos centramos en el último tipo, aplicada al líder de Hezbollah. El carisma, según este autor, es:

Una cierta cualidad de una personalidad individual, en virtud de la cual se le distingue de las personas comunes y se le dota de poderes o cualidades sobrenaturales, sobrehumanas o, al menos, excepcionales. Estas son de tal característica que no son accesibles a una persona ordinaria, sino que se consideran de origen divino o ejemplar, y sobre esta base el individuo en cuestión es tratado como un líder (Weber, 1947).

La autoridad carismática se basa en la "devoción a la excepcional santidad, heró́smo o carácter ejemplar de un individuo y a los patrones normativos u orden revelados por esa persona en particular" (Weber, 1968). Este tipo de autoridad puede poner en entredicho, por sus características, la autoridad tradicional o legal. House (1977) definió este tipo de liderazgo como aquel caracterizado por una persona dominante, con un fuerte deseo de influenciar a otros, seguro de sí mismo y con un marcado sentido de la moralidad. Este tipo de líder consigue despertar el entusiasmo de las personas que le siguen, quienes asimilan sus valores como propios. 
El auge de Nasrallah en los años de contiendas militares, especialmente en el 2006, proviene del hecho de que, en una situación de caos, los individuos buscan un referente de "absoluta confianza" porque los ven como la personificación del proceso mismo del cambio (Lepsius, 1986). La opinión favorable del líder es importante en casos donde el poder se encuentra tan claramente: mientras haya una revolución no habrá una contrarrevolución (Bueno, 2013: 93). Todos los dictadores han logrado mantenerse en el poder apartando a los rivales, de uno u otro modo, y aportando una pátina de legitimidad a través del discurso público. Pero en un sistema democrático, como en el caso que nos ocupa, el discurso hegemónico de Nasrallah tiene una doble vertiente: la interna, de cara al aparato del partido, y la externa, en el juego de votos democrático.

En este sentido, Sánchez (2005) apunta un diagnóstico del discurso político democrático con las siguientes características: la hegemonía de lo verosímil, la manufactura artificial de necesidades, el protagonismo de lo anecdótico y rocambolesco, la idea de vencer (electoralmente) como único fin, el abuso del corto plazo, la exclusión como audiencia de los públicos no capaces de otorgar el voto, la desmesura de la importancia de la tecnología, la personalización y la ambigüedad ideológica.

Nuestro análisis debe a su vez adaptarse al momento que estudiamos. La cultura masiva, los medios de comunicación y el conocimiento superficial, múltiple y simultáneo, obligan a un determinado tipo de intervención discursiva por parte de los políticos. Sus declaraciones tienden a ser breves, contundentes, seccionables y seleccionables (Rivera, 2006). Al final, queda la frase memorable, el breve adagio repetido y discursivo: no son argumentos, son consignas.

A la vez, Hezbollah no es solo un partido democrático, es considerado también una organización terrorista. Por esta razón, es también necesario observar su discurso teniendo en cuenta esta faceta. Según Pinto (2017), la propaganda terrorista persigue tres objetivos: la notoriedad, la persuasión y la intimidación. Con la notoriedad, busca hacerse un hueco en el imaginario cotidiano de los habitantes sometidos a su influjo. La persuasión cumple la misión de hacer hincapié en la veracidad y bondad de su mensaje. Si ésta falla, se puede conseguir el mismo efecto mediante la intimidación, es más, la complementa.

Estos tipos de propaganda son correlativos a la actuación real y armada. En el caso de la propaganda de notoriedad, las acciones terroristas suelen ser indiscriminadas, mientras que para la persuasiva e intimidatoria es todo lo contrario. Se precisa demostrar poder y control de la fuerza, con que solo con la amenaza de su uso resulte efectiva. Los mártires y héroes son los que validan de igual medida estos últimos tipos de mensajes.

En cuanto a la finalidad de la propaganda se podría dividir en la destinada a la conversión (mediante la persuasión y la argumentación, aunque sea falaz); la de división, que persigue debilitar al enemigo y su imagen; y la de consolidación, que intenta reforzar los logros y así mantener la base social (Pinto, 2017).

En resumen, la propaganda terrorista, en general, tiene dos misiones: la captación y la fidelización (Rey, 2017), aunque se enmarca en un paradigma más amplio de misiones de la comunicación, como son la extracción de datos e inteligencia, la recaudación de fondos, el reclutamiento y la formación, o el trabajo en red, planeamiento y coordinación del grupo. La propaganda, para Weimann (2004), está 
al mismo nivel que cada una de estas funciones, en un apartado que él llama "guerra psicológica, publicidad y propaganda".

\section{La figura de Nasrallah}

Hassan Nasrallah (Bourj Hammoud, 1960) es un líder carismático y tempestuoso, capaz de llevar a la guerra a su pueblo... y al vecino. Sus incendiarios discursos, animando a los palestinos a seguir el ejemplo de la resistencia de Hezbollah frente a Israel fueron yesca arrimada al ascua. Éstos generaron un estado de opinión que solo necesitó de la visita de Ariel Sharon a la explanada de las Mezquitas para que estallara la Segunda Intifada (Sánchez \& Rodríguez, 2009). Sus mensajes son los más seguidos, con un asombroso índice de credibilidad no solo entre los chí́es sino entre el resto de musulmanes (Sánchez \& Rodríguez, 2009). Por su boca habla no solo Hezbollah, sino el propio estado libanés. En un discurso del 14 de julio del 2006 llega a decir que "nuestras armas son la garantía de defensa del país contra Israel" (Nasrallah, 2006).

La aportación de Nasrallah al conflicto del Líbano fue, en principio, ideológica. En la Guerra Civil se decantó por unirse a Amal, el movimiento fundamentalista del jeque Musa Sadr; esto supuso una anomalía, pues los chiíes se habían decantado por movimientos de carácter socialista o marxista. Inició sus estudios religiosos en 1975 en Nayaf con Abbas al-Mussawi, eminente teólogo chií, y completó en 1978 su formación en la histórica ciudad de Qom, en Irán, donde conoció entre otros a los futuros ayatolas Jomeini y Jamenei, así como al sayyid (descendiente de Mahoma) Mohammed Sadeq al-Sadr, todos ellos figuras imprescindibles del chísmo actual. Con la entrada de Israel en el Líbano en 1982, Nasrallah abandona Amal y gracias a la financiación iraní logra poner en pie una nueva organización armada, Hezbollah.

Nasrallah sucede en la Secretaría General a Abbas al-Mussawi, tras su muerte a manos de los israelíes en 1992. Su estrategia ha sido precisamente eso, hacer primar la política por encima de la religión. Su lucha con su hermano Khader, que permanecía en Amal, o la pérdida en combate de su hijo Hadi en 1997, cimentaron un aura de héroe. Por una parte, es incuestionable su aptitud militar: logró provocar y luego salir airoso frente a las $\mathrm{FDI}^{3}$ en tres operaciones de gran calado: Operación Responsabilidad (Mivtza Din VeHeshbon), en 1993, Guerra de los Siete Días para los libaneses; la Operación Uvas de la Ira, en 1997, Guerra de Abril en el Líbano; y la Guerra del Líbano de 2006. Pero por otra parte es un hábil político, que utiliza todos los recursos a su alcance, bien sea la oratoria, la demagogia, el recurso a los sentimientos religiosos y nacionales y cualesquier técnica que permita el control de sus fieles; para ello también en innegable que les ha proporcionado un sustento social (sanidad, educación, pensiones), algo especialmente reseñable en una sociedad extremadamente deficitaria en estas cuestiones como la libanesa.

Hezbollah, por medio de Nasrallah, se declaró al margen de los acuerdos de Taif que pusieron fin a la guerra, puesto que entendían que su lucha era contra la ocupación israelí. Esto se cumple en el año 2000, con la aplicación de la Resolución 425 (Consejo de Seguridad de las Naciones Unidas, 1978), pero existe un territorio en disputa en los Altos del Golán, de unos 10 kilómetros cuadrados, ocupado al 
Líbano por Siria y posteriormente a este último por Israel, las Granjas de Shebaa (Djebel Sheijk en árabe), con 14 asentamientos. La ONU entiende que la soberanía es siria, pero Hezbollah pretende encontrar en estas granjas el motivo para continuar la lucha armada en la actualidad. Y a ello dedica sus esfuerzos comunicativos.

\section{El discurso televisivo}

Las apariciones públicas de Nasrallah se dan siempre en un contexto de anticipación. Hezbollah controla prensa, un canal de televisión propio (Al-Manar) y páginas web, que anuncian cuándo habrá un discurso. Un discurso público ayuda a reforzar el consenso del público al establecer, por medios visuales y auditivos, las ideas clave que el político exprese a la vez que replantea cómo el receptor se percibe en relación a él.

El proceso de mediación, como sugiere Pels (2003), puede crear una sensación de falsa intimidad entre el líder y los liderados. En este caso, la intimidad se crea por varios mecanismos. Nasrallah habla mirando directamente a la cámara, rompiendo la cuarta pared y la distancia con el espectador (Figura 1).

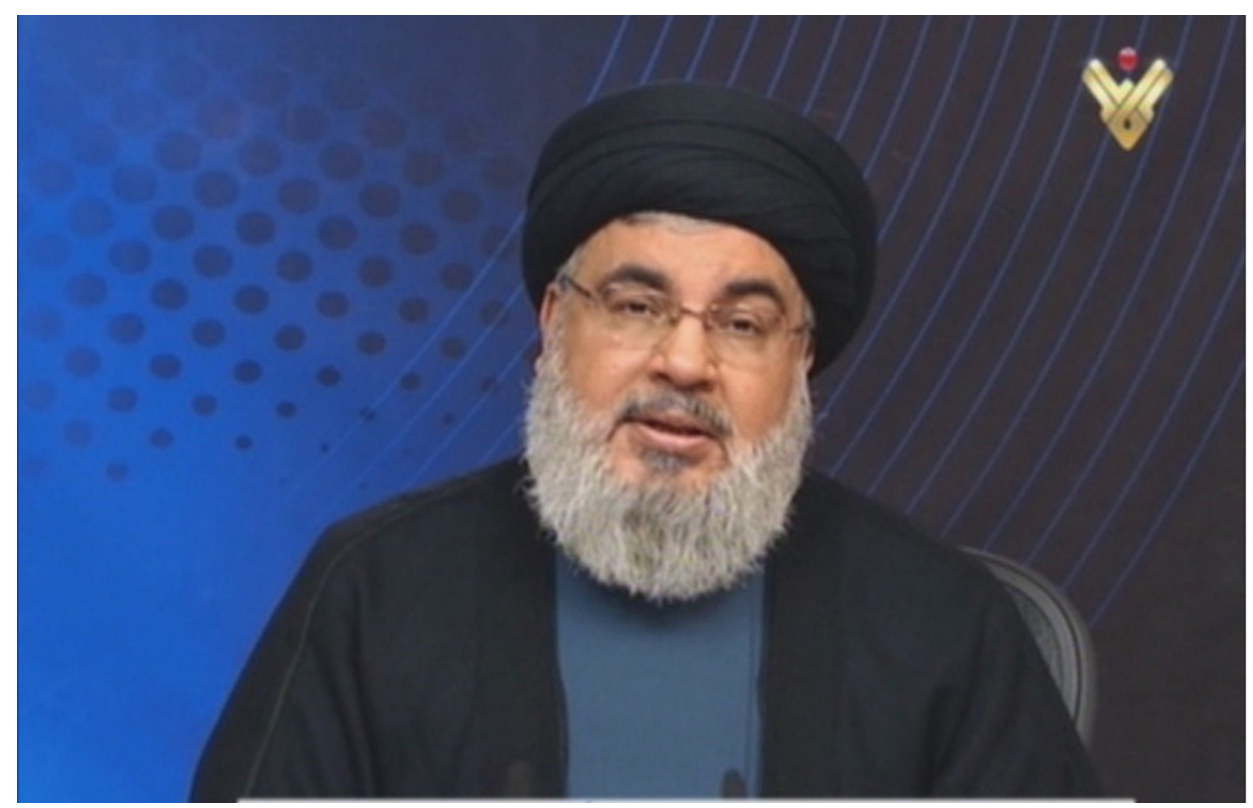

Figura 1: Nasrallah en su discurso del 6 de Noviembre del 2017. Fuente: https://english. almanar.com.lb/379546

La mirada fija hacia el espectador da la sensación de que se dirige únicamente a él. A diferencia de los noticiarios televisivos, que también utilizan la mirada directa hacia la cámara, Nasrallah no lee de un teleprompter, sino que habla sin apoyo escrito 
frente a la óptica. En ocasiones se le puede ver refiriéndose a notas que tiene sobre la mesa. Este gesto, da sensación de mayor naturalidad que la mera lectura, basando la oratoria en la posesión de unos puntos clave claros e improvisando el discurso.

El encuadre siempre es fijo y con cámara única, sin cortes a otros ángulos, en tamaño de plano medio corto, que corta su figura por mitad del brazo. Los fondos también son estáticos. Éstos suelen ser abstractos y de color azul, aunque hay casos de grises o rojos. Los fondos pueden presentar texto sobreimpresionado, con un pequeño diseño gráfico, ambos estáticos y siempre detrás de la figura del orador.

Estos planos se intercalan, en el discurso del 22 de septiembre del 2006, con los de la muchedumbre que acude a presenciarlo. Se les muestra al inicio y al final, recalcando la amplitud del gentío mediante planos desde gran altura. Posteriormente, se intercala su sonido de aprobación o repulsa hacia lo que indica Nasrallah, y se pasa a mostrarlos. Esta imagen suele presentarse en forma de multipantalla, con dos perspectivas diferentes de los asistentes, que dan todavía mayor sensación de aglomeración. La introducción de imágenes de espectadores solo se da en grandes ocasiones o discursos relativos a fechas festivas. Durante los discursos que no se dan por estas excepciones, el plano es fijo e inamovible sobre Nasrallah.

Los discursos siguen una estructura predefinida. En primer lugar, empieza utilizando fórmulas religiosas de bienvenida y referencias al Corán. En segundo lugar, explica por qué se dirige hoy a la audiencia y declara qué puntos que va a tratar y cuáles no. Puede, en este momento, confirmar que los tratará en discursos posteriores. Después, en tercer lugar, procede a desarrollar su exposición. En cuarto legal, cierra el discurso con recomendaciones a la audiencia y pensamientos finales sobre lo expuesto. En la despedida, no realiza una extensa referencia religiosa.

El lenguaje utilizado oscila entre el árabe formal y el dialecto libanés. El árabe

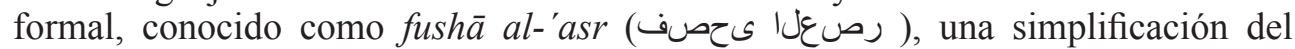
árabe coránico que unifica el idioma. Es principalmente un medio de comunicación escrita, pero se utiliza también en televisión. El dialecto libanés, por otra parte, es un medio oral que no se ve reflejado (con contadas excepciones) de forma escrita ni en medios. Incluso dentro del país, no es utilizado por toda la población, puesto que hay grupos sociales que recurren al francés o al inglés como lengua principal, aunque con expresiones árabes intercaladas.

Nasrallah hace uso de ambas lenguas. La gran mayoría de su discurso se da en fushā al-'asr pero cuando habla directamente a los cercanos a su organización o realiza un comentario sarcástico, remite al dialecto libanés. El sentido del humor no está exento de sus discursos, recurriendo incluso a fórmulas religiosas en tono jocoso. En el discurso del 22 de septiembre del 2006 hace una referencia a la Canciller alemana, Angela Merkel, y dice un equivalente de "Dios la bendiga" con una sonrisa sardónica. 


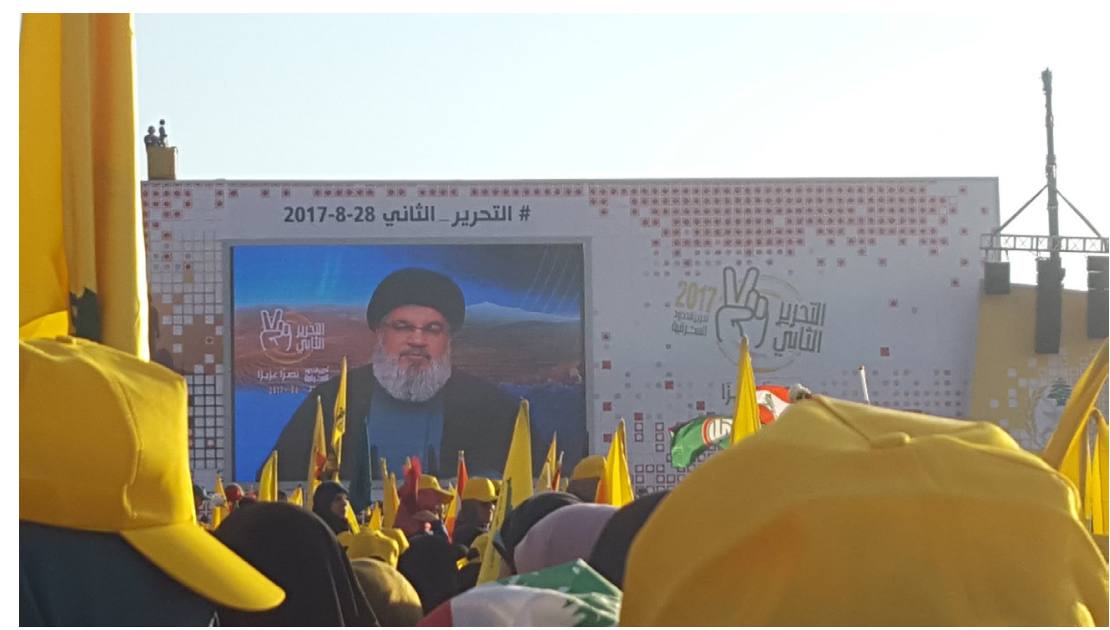

Figura 2: Sayyed Nasrallah en el discurso del 31 de agosto del 2017.

Fuente: https://english.almanar.com.lb/339755

Los discursos se dan casi siempre desde espacios cerrados y ajenos a espectadores en directo, en caso de haber una reunión pública para el evento. Si la hay, suele comparecer desde una pantalla de gran tamaño, como puede verse en la Figura 2, que corresponde al 31 de agosto del 2017. En el discurso del 22 de septiembre del 2006 hace mención a su necesidad de presentarse ante su gente y no hablarles desde la distancia. Este discurso, excepcional por sus características, parece efectivamente estar rodado en el lugar de reunión.

La cámara, con una óptica de distancia focal larga, en ocasiones oscila por lo que parecen ser golpes o movimientos del operador de cámara. Este tipo de movimiento puede darse por rodar con teleobjetivos sobre un trípode de estabilidad relativa, como podría ser uno situado a su máxima altura. Al final del vídeo se puede ver el escenario del discurso y, en el plano general de la audiencia, parecen entreverse otros dos más, quizá con pantallas o como distracción por si se intentase un asesinato.

En lo referente a temática, siempre versa sobre hechos militares y políticos de actualidad. En su oratoria una serie de contenidos son comunes: la resistencia, el martirio, la soberanía nacional y la unidad del pueblo. De la resistencia se habla en términos positivos desde el lado humano y con insistencia en la potencia militar. El martirio, no un tema exaltado en sí mismo, aparece en forma de "justa" venganza: se resarcirán todas las afrentas a aquellos dañados. La soberanía nacional y la necesidad de un gobierno justo se utiliza como crítica al gobierno actual el país, al que se solicita que quede libre de corrupción y aquellas medidas que concuerdan con el ideario de Hezbollah. El texto intenta ser inclusivo, para atraer a gente de otras religiones, en consonancia con los textos fundacionales del grupo (Hezbollah, 1985).

El lenguaje es inclusivo, utilizando el "nosotros". Por ejemplo: "Hemos cumplido una primera misión con éxito, la de erradicar al Frente al Nusra de Arsal" (Al-manar, 2017a); "Somos una fuerza destructiva contra todos sus proyectos de división y 
guerras" (Al-manar, 2017b). Dentro de una línea ensalzadora del grupo, se puede citar también:

Los movimientos de resistencia no se debilitarán. Somos más fuertes que nunca; somos más numerosos; estamos mejor armados y estamos más decididos a resistir contra los enemigos. (Almanar 2017c)

La mención a la fuerza militar es frecuente. Cada éxito de este tipo va unido a un discurso a su alrededor. El 5 de agosto del 2017 dio un discurso sobre la erradicación de Al-Nusra de Arsal. En él, No solo se menciona una victoria sino que se promete la continuidad de la acción:

Hemos cumplido una primera misión con éxito, la de erradicar al Frente al Nusra de Arsal y de su campo, y hoy tenemos una nueva misión que cumplir: la de erradicar al EI del campo de Qaa y de Ras Baallbeck. (Al-manar, 2017a)

En otros casos se busca reforzar la memoria de logros pasados como justificación de la continuidad de la fuerza actual. Este tipo de argumentación funciona también como validación de la verosimilitud de la información dada por el líder, puesto que son hechos históricos corroborables. Podemos citar a este respecto, como ejemplo, el siguiente texto:

Nosotros recordamos, como en cada año, los mismos hechos para que las nuevas generaciones se beneficien de ellos. Cuando el enemigo israelí invadió el Líbano, el mundo nos abandonó. Las facciones y partidos libaneses y palestinos tomaron la decisión de afrontar al enemigo. La resistencia fue entonces iniciada y en el año 2000 logramos la victoria. (Al-manar 2017c)

No hay menciones, como sucede en los discursos democráticos, de una intención de vencer en elecciones puesto que como líder de Hezbollah no pasa por este proceso. No hay exclusión directa de aquel público que no le apoya, puesto que se refuerza la inclusión de todo el posible público.

\section{La cartelería}

Desde la Guerra del Líbano, y al igual que en otros conflictos como la Guerra Civil española, la cartelería ha sido un vehículo básico de la propaganda (Maasri, 2009) y todavía en la segunda década del siglo XXI sigue siéndolo. Nasrallah aparece hoy, de manera omnipresente, en multitud de carteles repartidos por toda la geografía del Líbano, al norte y el sur del Litani, y en las paredes de casi todas las ciudades del país. Los carteles se pegan en muros, se cuelgan de las farolas, cubren edificios o se portan en manifestaciones (Figuras 3 a 8 ). 

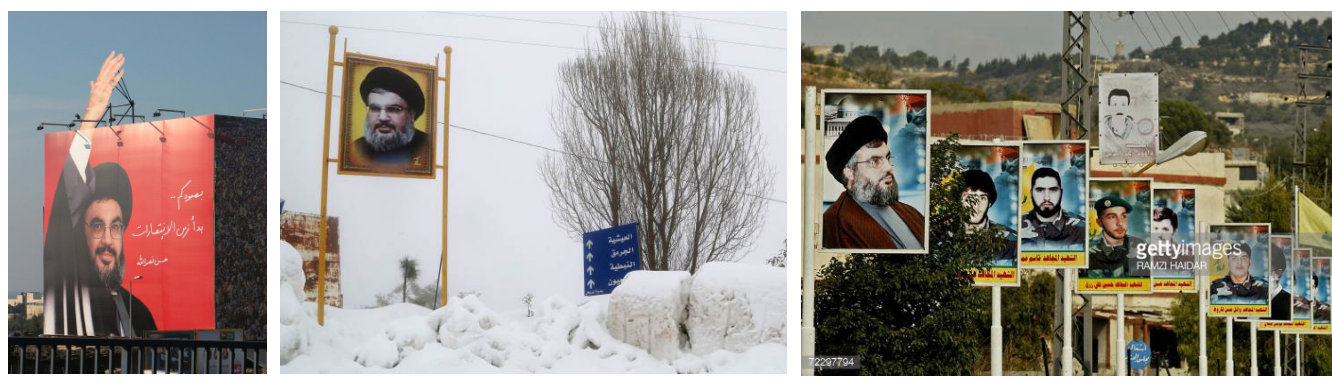

Figura 3: Aziz Taher, Reuters. Fuente: http://news.trust.org/

Figura 4: Ramzi Haidar, AFP. Fuente: Getty Images. http://www.gettyimages.com.au/ Figura 5: Poster en la carretera al aeropuerto que lee "Con nuestro tesón, la era de la victoria ha comenzado". Fuente: https://alhurr.com/
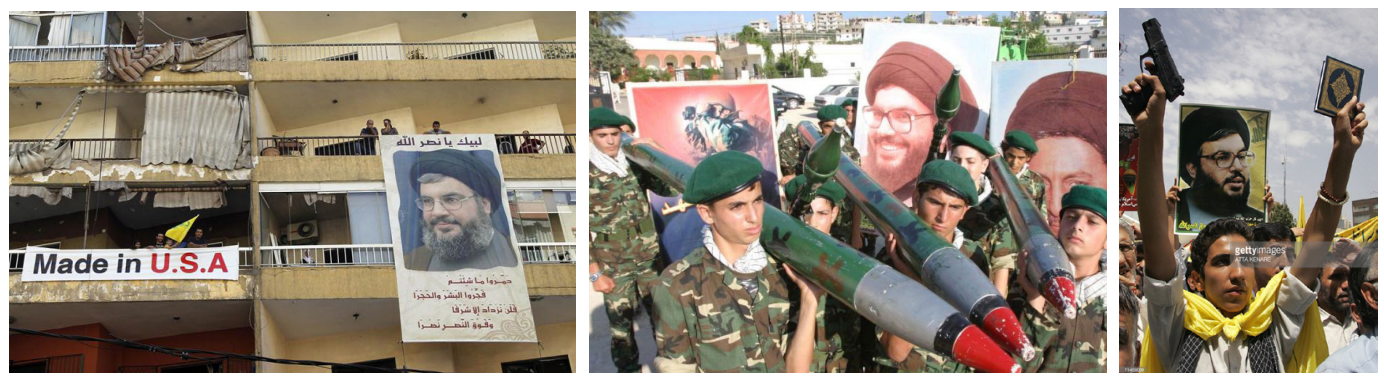

Figura 6: Atta Kenare, AFP. Fuente: Getty Images. http://media.gettyimages.com/

Figura 7: Reuters. Jerusalem Post. Fuente: http://www.jpost.com/

Figura 8: Al-Anwar Amro, AFP. Al-Akhbar English. Fuente: http://english.al-akhbar.com/

En esos carteles Nasrallah aparece en ocasiones como figura única, sin más que su retrato, acompañado generalmente de un copy, un texto reafirmativo. Como en toda buena operación hagiográfica, se le muestra en diversas poses que acentúan su capacidad de líder, siendo las más frecuentes las sonrientes y pensativas, lo que contrasta con la imagen generada a través de los discursos hablados (Figuras 9 a 11). 

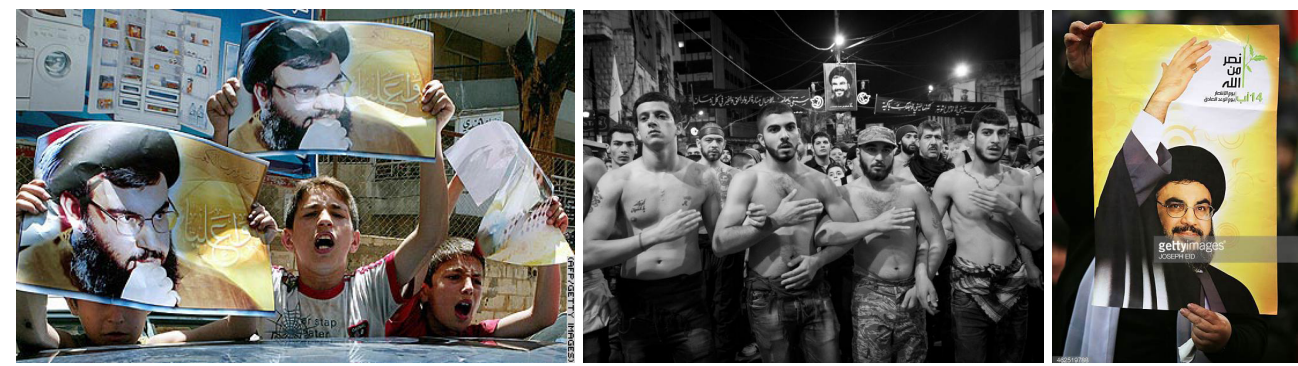

Figura 9: Joseph Eid, AFP. Fuente: Getty Images. http://www.gettyimages.es/

Figura 10: Fuente: https://en.qantara.de/

Figura 11: Innovative Minds. Fuente: http:/www.inminds.com/

En otras ocasiones Nasrallah aparece en compañía de otros líderes políticos o religiosos con los que comparte las líneas maestras de su ideología. Uno de los más frecuentes es el Imán Jamenei, líder espiritual iraní, pero en el contexto de guerra en Siria, el rostro más repetido actualmente es el de Bashar al-Assad. Junto a él aparece en ocasiones su padre, Hafez al-Assad, o el presidente ruso Vladimir Putin (Figuras 12 a 14).
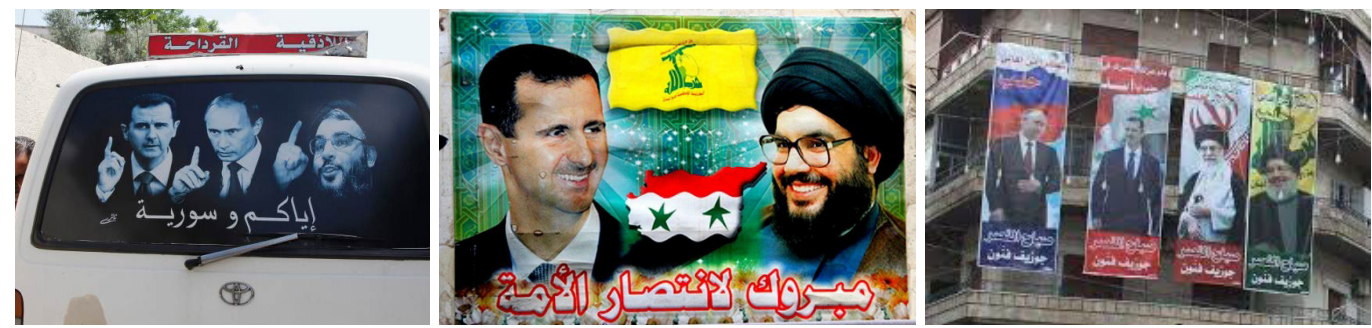

Figura 12:@Yallalr7al. Fuente: Twitter. https://witter.com/YallaIr7al/

Figura 13: Trackpersia. Fuente: http://www.trackpersia.com/

Figura 14: Khaled al-Hariri, Reuters. Business Insider.

Fuente: http:/www.businessinsider.com/

El formato elegido para compartir protagonismo es muy variado. Puede ser la simple yuxtaposición de retratos individuales, a composiciones conjuntas, buscando equilibrio y simetría. Nasrallah suele aparecer en el lado derecho de la composición, lo que puede ser debido a la posición de primacía que implica la lectura árabe, de derecha a izquierda (Figuras 15-17). 

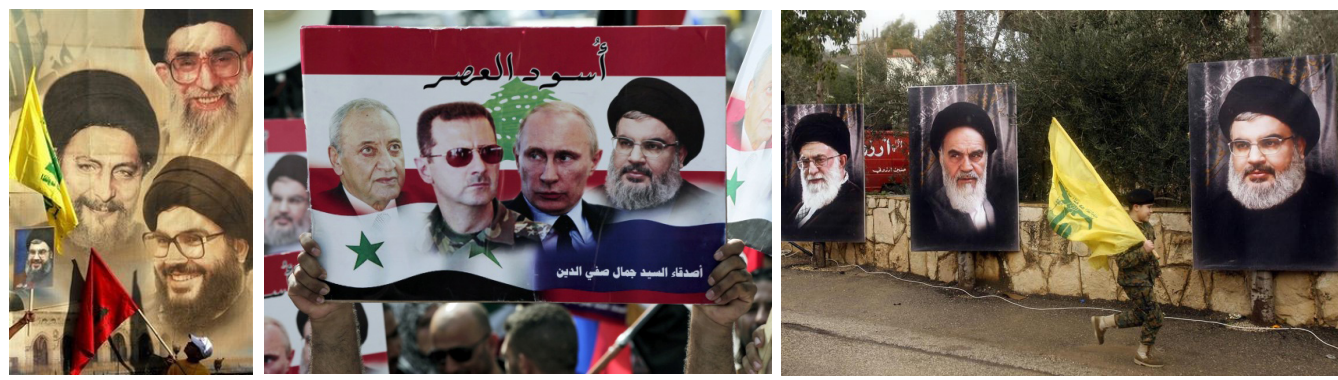

Figura 15: Forward, Fuente: Getty Images. https://forward.com/

Figura 16: Pbs.org. Fuente: https://www.pbs.org/

Figura 17: Handelsblatt. Fuente: http://www.handelsblatt.com/

Menos representados, pero con una cierta intensidad, aparecen los rostros de Nabih Berri, el presidente del otro gran movimiento chií libanés, Amal; del líder venezolano Hugo Chávez o de Abdul Malik al-Houti, hermano del inspirador de la insurgencia chií en 2004 en Yemen, Hussein Badr Eddin al-Houti (Figuras 18 a 20).
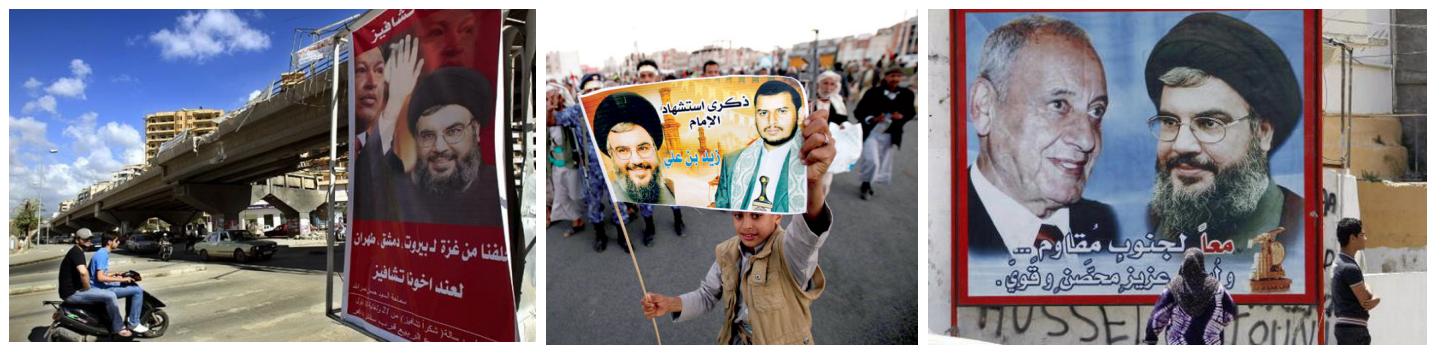

Figura 18: Write in the Global Jungle. Fuente: https://writeintheglobaljungle.com/

Figura 19: Press TV. Fuente: http://www.presstv.com/

Figura 20: Reuters. The Arab Weekly. Fuente: http://www.thearabweekly.com/

En un nivel de lectura más profundo, se debe admitir la complejidad simbólica de la cartelería de Hezbollah, en general, y la referente a Nasrallah en particular. El color amarillo, propio del partido, se combina en ocasiones con el verde del islam o de Amal. El uso semiótico de la lengua árabe permite crear el anagrama de Hezbollah con caligrafía moderna, y éste suele estar presente en los carteles (Figuras 21 a 23). El cartel de la figura 21 es representativo de la complejidad significativa: la imagen de fondo se corresponde a uno de los bombardeos israelís sobre Beirut en 2006, y es una de las poquísimas ocasiones en las que aparece -en cartelería- un Nasrallah iracundo. Lo que por otra parte, permite una doble intención: el dedo levantado es a la vez que símbolo universal de reprensión, la mención musulmana a la unicidad de Dios. El cartel de la Figura 22, además de la duplicidad del protagonista, muestra el anagrama de Hezbollah convertido en estatuilla dorada tridimensional. Por último, el cartel de la Figura 23 muestra la compleja interacción entre El Líbano e Irak, con las imágenes de Muqtada al Sadr, clérigo chií iraquí, y un Nasrallah que porta sobre los hombros una kfiya palestina, ambos sobre imágenes de milicias chiíes. Como vínculo entre ambos, la bandera de Hezbollah. 

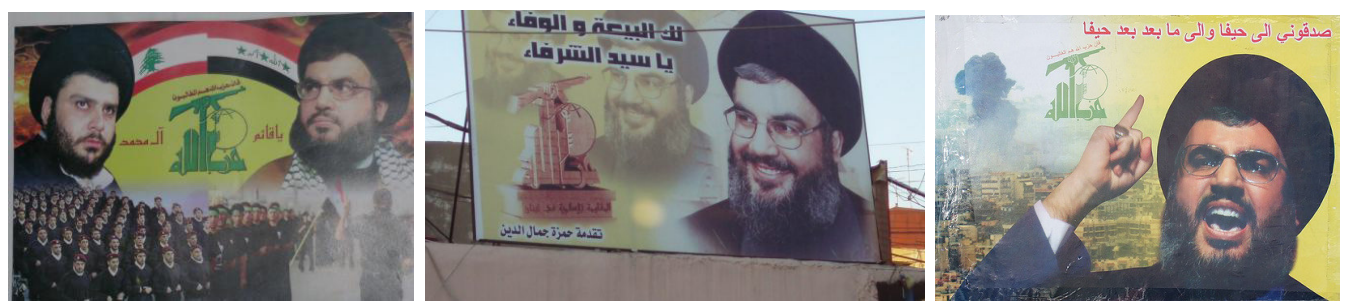

Figura 21: Flickr. Rubincenter. Fuente: http://www.rubincenter.org/

Figura 22: The National Discourse. Fuente: http://thenationaldiscourse.com/

Figura 23: Trident Military. Fuente: https://www.tridentmilitary.com/

No se puede finalizar este somero análisis de la comunicación mediante cartelería de la imagen de Nasrallah sin mencionar la función última del simbolismo que se persigue: el jeque es la continuidad del proyecto panislámico de Nasser, y es capaz de sumar a ese proyecto a líderes que ni siquiera son musulmanes, como Chávez (Figura 24). Del mismo modo, Nasrallah sirve de puente entre la idea partidista y la idea nacional, y resume la esencia del Líbano: su retrato está bajo ambas banderas, la de su partido y la de su país (Figura 25). A la vez, superando la idea nacional, un tanto ajena al mundo musulmán, está el ideal supremo, la unificación en torno a los Santos Lugares. No suele ser frecuente ver más que la cabeza o el busto del jeque, pero en el caso de la Figura 26 aparece una composición compleja, la simbología complicada a la que hacíamos referencia antes: Nasrallah sostiene un AK-47, el arma revolucionaria por excelencia, sobre el fondo de la cúpula de Al-Aqsa, en Jerusalén. La cúpula de la Mezquita de la Roca es por otra parte recurrente en la iconografía de Hezbollah, y suele estar muy presente junto al jeque. (Figura 27)
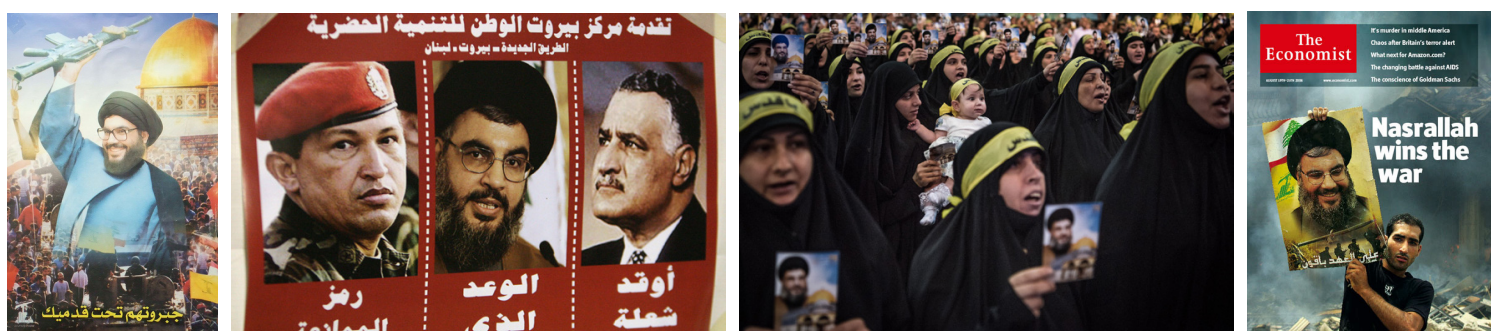

Figura 24: The Counter Jihad Report. Fuente: https://counterjihadreport.com/

Figura 25: The Economist. Fuente: http://www.economist.com/

Figura 26: Fuente: http://www.e-ir.info/

Figura 27: Sergey Ponomarev. New York Times. Fuente: https://www.nytimes.com/

Por último, cabe citar el protagonismo de Hadi Nasrallah, el hijo de Nasrallah, que aun siendo menor, ha proporcionado una suficiente aura de compromiso a su padre y a la organización, debido a la condición de mártir que alcanzan los caídos por la causa. Hadi Nasrallah murió en combate con los israelíes en Jabal al-Rafei, en el sur del Líbano, a mediados de septiembre de 1997. Su imagen aparece como fondo de los discursos de su padre, o bien compartiendo protagonismo en cartelería; en otras ocasiones aparece también en solitario (Figuras 28 a 30). 

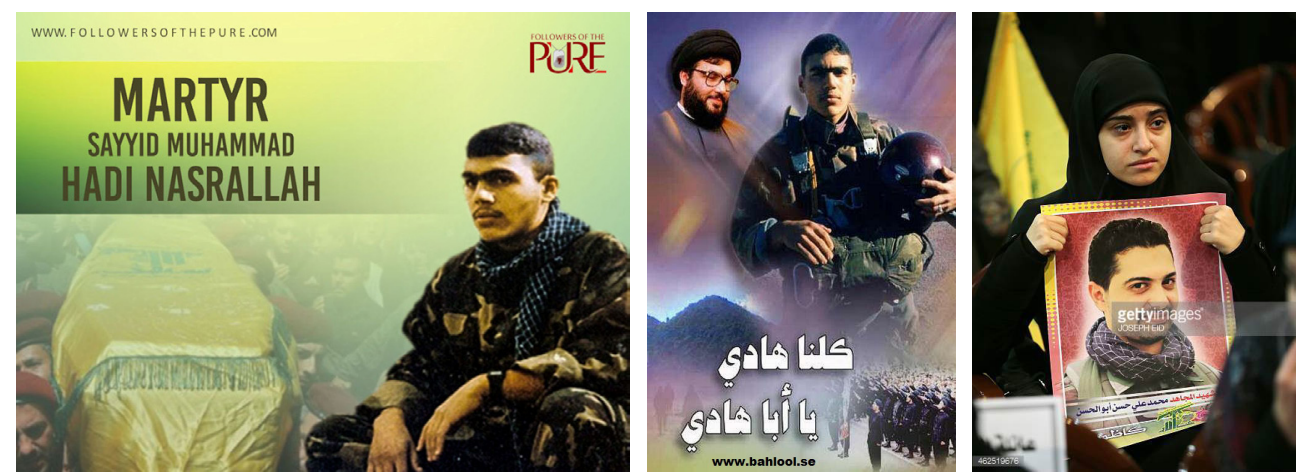

Figura 28: Joseph Eid, AFP. Fuente: Getty Images. http://www.gettyimages.es/

Figura 29: Bahlool. Fuente: www.bahlool.se/

Figura 30: Followers of the Pure. Fuente: https://followersofthepure.com/

\section{La imagen del líder a través del ocio: el parque de atracciones}

Mleeta Landmark es un híbrido entre museo, monumento conmemorativo y parque de atracciones; de hecho, el proyecto original prevé un parque acuático y un conjunto de hoteles en derredor, así como campings y merenderos (Mleeta, 2017). En el sur del Líbano, pocos kilómetros a vuelo de pájaro de Kyriat Shmona, Israel, se encuentra una colina verde bien cuidada, que durante la guerra de 1982-2000 sirvió de centro de mando. Está estratégicamente cerca de Iqlim al Tuffah, uno de los centros neurálgicos de la resistencia, y es una altura dominante. Mleeta sirvió de acuartelamiento, si por tal se entiende una red de túneles subterráneos, para los muyaidines de Hezbollah. Si en algún momento pudo ser un símbolo de la resistencia, hoy lo es de manera efectiva.

Tras un enorme aparcamiento, una avenida amplia jalonada de sombra y flores conduce a las salas donde se exponen vídeos de bienvenida, con una somera historia del largo conflicto libanés-israelí. El jeque Nasrallah aparece en ellos, admonitorio y ceñudo incluso en el triunfo. A la salida de los audiovisuales se visita una exposición con armas capturadas a las FDI, así como diagramas y planes de batalla, entre los que destaca un inmenso organigrama con la disposición y nombre de las fuerzas enemigas, en un alarde de las capacidades de la inteligencia desplegadas por Hezbollah, que era capaz de conocer al enemigo.

La visita es guiada siempre por un acompañante, que de manera cercana, amable, emotiva y personal cuenta su visión del conflicto. Suelen ser guías implicados, bien de manera directa en los combates, bien como víctimas de las diferentes guerras, bien de ambos modos. Sus historias, verídicas y duras, explican el sesgo de su discurso. Es difícil no sentir empatía. Los guías traban, además, trato cercano con los visitantes: se interesan por sus familias y ocupaciones, intentan responder a todas las dudas, están atentos al cansancio, a la sed y al calor.

El parque está orientado al visitante múltiple: a los niños se les permite jugar entre los restos de carros de combate, todo se puede tocar, y hay incluso atracciones hinchables para desfogarse. El visitante adulto encontrará un gusto estético en la 
disposición de los elementos del sitio conmemorativo, tanto en cuanto a arquitectura como a los diferentes monumentos, esculturas o instalaciones artísticas. El interesado en la historia podrá visitar los túneles y emplazamientos originales de la guerra de 2006, con ese aroma que desprenden los campos de batalla.

El recorrido tiene un carácter simbólico. Se comienza en el "Abismo", un foso donde varios carros de combate se oxidan entre munición y cascos israelíes; se cuentan $\mathrm{APCs}^{4}$, antiaéreos y todo tipo de material bélico tomado al enemigo, siendo la estrella un Merkava, con el cañón anudado. La "Senda" discurre por entre el monte a diversos nichos de ametralladora, puntos fuertes y escenas reconstruidas con maniquíes, y conduce a la "Cueva". El recorrido subterráneo muestra un oratorio, alojamientos, cocinas, polvorines, y acaba en un punto de observación donde entre banderas la mirada cae hasta los pueblos de Zahrani, Nabatiyeh, Saida o Sour. Vuelta atrás, por diferente camino, hacia los edificios, la "Línea de Fuego" está jalonada por armamento usado por Hezbollah, en impecables condiciones, que acaban en la "Plaza de la Liberación". Desde ella se asciende a la "Colina", el puesto de observación más alto, que al a vez simboliza la ascensión de los mártires al paraíso. Este recorrido espiritual se ve complementado por la tienda de recuerdos, preludio de una planificada futura cafetería, que devuelve al visitante al ámbito terrenal.

\section{Conclusiones}

Se puede considerar que Hassan Nasrallah cumple las funciones de líder carismático como Secretario General de Hezbollah, según la definición de Weber y los apuntes realizados por House a ésta. Es imprescindible en la política comunicativa del grupo Hezbollah. A pesar de ser un Secretario General más, entre otros, su carisma y su presencia le convierten en una figura cercana a la de un líder carismático. Hezbollah ha sobrevivido una vez a la eliminación de su líder, pero en estas circunstancias la pérdida de Nasrallah sería un golpe terrible. Aunque solo sea por cuestiones de imagen.

En un país con redes de comunicación de internet poco desarrolladas que todavía recurre a esquemas comunicativos tradicionales, la cartelería, eslóganes pintados en paredes y la presencia gráfica juegan un papel importantísimo. La imagen de Nasrallah es omnipresente en estos ámbitos. El jeque es el presente, es el pasado y es el futuro. Es la política actual, es la resistencia del ayer y es el ideal del compromiso y la religión.

Se le dibuja como un hombre cercano, amable y sonriente. Si se enfada es por el bien de su propio pueblo, del que cuida. Habla el árabe coloquial y a la vez el fushā al-'asr; domina el sentido del humor, y es capaz de ironizar sobre conceptos religiosos. Es tan cercano que hace sentir como propio al relapso, al cristiano, al libanés de otra religión. Sabe hacer compartir un ideal, bien sea de soberanía nacional, bien sea de renovación política, exigiendo la renuncia a la corrupción. Cualquiera puede compartir sus ideas, de manera que incluso el occidental se siente seducido cuando Nasrallah apela a la defensa del mundo civilizado frente a la barbarie de Al-Nusra o el Daesh, a los que hizo frente Hezbollah.

La amabilidad, con finalidades de captación y fidelización, es una estrategia a la que también se recurre en otras ramas derivadas de la comunicación. El Mleeta Landmark 
busca estos objetivos con audiencias de todas las edades, mediante la colaboración de los guías del lugar y el trato cercano que dispensan a los visitantes.

Nasrallah se revela también como una figura omnipotente. Su carácter de sayyid lo convierte en especial, porque es el guía religioso. No solamente comanda un movimiento guerrillero, una facción política o una asociación social (pues Hezbollah es todas esas cosas a la vez), es también el líder espiritual de los chí́es del Líbano. Nasrallah, además, encarna la historia viva de la resistencia, donde demostró sus dotes militares, y es el padre provisor: desde hospitales a sistemas de pensiones. Su discurso combina la oratoria propia de grupos terroristas con los rasgos de los democráticos, con la excepción de no requerir el voto de los que le escuchan, puesto que se sitúa al margen de la lucha política: Hezbollah tiene dos ministros actualmente en el gobierno libanés, pero ambos son figuras de segundo orden. El jeque se reserva para misiones más elevadas.

Este texto surge dentro del marco del Proyecto de Investigación UCM-Santander. Referencia: PR26/16-6B-1, titulado: PERLAD, Pensamiento y representación literaria y artística digital ante la crisis de Europa y el Mediterráneo.

\section{Bibliografía}

Al-manar. (2017a). Sayyed Nasralá: El Frente al Nusra ya no existe en el Líbano. Ahora es el turno del EI. Recuperado de: http://spanish.almanar.com.lb/110255 (Fecha de acceso: 4/12/2017).

Al-manar. (2017b). Sayyed Nasralá: La Resistencia libanesa es hoy más poderosa que nunca. Recuperado de: http://spanish.almanar.com.lb/113082 (Fecha de acceso: 4/12/2017).

Al-manar. (2017c). Sayyed Nasralá: Somos mucho más fuertes. La cumbre de Riad no tendrá ningún efecto. Recuperado de: http://spanish.almanar.com.lb/88167 (Fecha de acceso: 6/12/2017).

Consejo de Seguridad de las Naciones Unidas. (1978). Security Council Resolution 425 [Israel-Lebanon], S/RES/425. Recuperado de: http:/unscr.com/en/resolutions/ doc/425 (Fecha de acceso: 5/12/2017)

Hezbollah. (1985). "Nass al-Risala al-Maftuha Allati Wajahaha Hezbollah ila-1-Mustad'afin fi Lubnan wa-1-Alam". Al-Safir, 16 de febrero.

House, Robert. (1977). “A 1976 Theory of Charismatic Leadership”. En James G. Hunt y Lars L. Larson (ed.), Leadership: The Cutting Edge. Carbondale: Southern Illinois University Press.

Hubbard, Ben. (2017) "Iran out to remake Mideast with Arab enforcer: Hezbollah", New York Times, 27 agosto 2017. Recuperado de: https:/www.nytimes.com/2017/08/27/ world/middleeast/hezbollah-iran-syria-israel-lebanon.html (Fecha de acceso: 6/12/2017).

Lepsius, Rainer. (1986). “Charismatic Leadership: Max Weber's Model and its Applicability to the Rule of Hitler". En Carl F. Graumann y Serge Moscovici (ed.), Changing Conceptions of Leadership, Nueva York: Springer-Verlag.

Maasri, Zeina. (2009) Off the Wall: Political Posters of the Lebanese Civil War. Londres: IB Tauris.

Mleeta Resistance Tourist Landmark. (2017), web oficial. Recuperado de: http://mleeta.com/ mleeta/eng/definition10.html. (Fecha de acceso: 11/12/2017). 
Nasrallah, Hassan. (2006). "Sayed Hassan Nasrallah - historic speech (14 July 2006)". Recuperado de: https://www.youtube.com/watch?v=01BZAZNQD_M (Fecha de acceso: 10/11/2017).

Pels, Dick. (2003). "Aesthetic representation and political style". En John Corner, Dick Pels (ed.), Media and the restyling of politics (pág. 41-67). Londres: SAGE.

Pinto, Fernando. (2017). Las razones de la sinrazón de los terrorismos contemporáneos (reflexiones sobre sus imaginarios). Madrid: Fundación Investigación Seguridad y Policía.

Rey García, Pablo; Rivas Nieto, Pedro; Sánchez Alonso, Óscar. (2017). "Propaganda, radicalismo y terrorismo: la imagen del DAESH”. Estudios sobre el mensaje periodístico, vol. 23, núm. 1, 209-221.

Rivera, Antonio. (2016). Antología del discurso político. Los libros de la Catarata: Madrid.

Sánchez Herráez, Pedro; Rodríguez Barrigón, Juan Manuel. (2009). El conflicto del Líbano. Madrid: Ministerio de Defensa.

Sánchez, Óscar. (2005). El servicio postventa de la política. Salamanca: Publicaciones Universidad Pontificia de Salamanca.

Weber, Max. (1947). Theory of Social and Economic Organization. Londres: Williand Hodge and Company Limited.

Weber, Max. (1968). Economy and Society: An Outline of Interpretive Sociology. Nueva York: Bedminster Press.

Weimann, Gabriel. (2004). www.terror.net: How modern terrorism uses internet. Washington: United States Institute of Peace. Disponible en: http://www.usip.org/sites/default/files/sr116.pdf 